FUN WITH FACEBOOK: THE IMPACT OF FOCUS GROUPS ON THE DEVELOPMENT OF AWARENESS CAMPAIGNS FOR ADOLESCENT HEALTH

Herron School of Art and Design

Indiana University - Purdue University Indianapolis

Helen Sanematsu, MFA¹, Stephanie Woodcox, MPH, CHES ${ }^{2}$, \& Vaughn I. Rickert, PsyD ${ }^{3}$

${ }^{1}$ Herron School of Art and Design, IUPUI; ${ }^{2}$ Division of Maternal and Child Health,
Indiana State Department of Health, ${ }^{3}$ Section of Adolescent Medicine,
Indiana University School of Medicine

\begin{abstract}
Efforts at improving adolescent health through mass communication are frequently undertaken by corporate design firms using traditional design development methods. While such methods may create work that is aesthetically significant, their effect on their intended audience is often overlooked in the process. Left unaddressed are youth media consumption, existing knowledge of health issues, and youth social patterns.
\end{abstract}

By conducting focus groups with local youth, we wanted to learn about 1) attitudes and prior knowledge about the areas identified in Indiana's Adolescent Health Plan, and 2) consumption of media and preferences in programming

\title{
Results
}

Knowledge of adolescent health issues

Designers learned first-hand youth attitudes toward adolescent health issues and relied on their findings to develop storylines, dialog, and casting decisions.

\section{Media consumption}

While television remains the most popular method of media consumption, social networking sites play a large role in determining what media youth consume. The connection to peers and information sharing enabled by Facebook presented the most potential for effective media development.

\section{Design deliverables}

These data resulted in development of public service announcements (PSAs) and a health survival booklet. PSAs resembled instant communication or 'chats' on Facebook and addressed topics of obesity, stress, vehicular safety, and substance abuse. The PSAs provide a familiar visual reference for youth while leveraging its social networking function for emotional impact. The booklets balance practical information with content intended to entertain as well as inform the reader. 